\title{
Bayes Açıortay Regresyon Tekniği ve Bir Uygulama
}

\author{
Ece ÖZGÖREN1®, Sinan SARAÇLI*2@ \\ ${ }^{1}$ Eskişehir Teknik Üniversitesi, Fen Fakültesi, İstatistik Bölümü, 26470, Eskişehir, Türkiye \\ ${ }^{2}$ Afyon Kocatepe Üniversitesi, Fen-Edebiyat Fakültesi, İstatistik Bölümü, 03200, Afyonkarahisar, Türkiye
}

(Alınış / Received: 10.03.2021, Kabul / Accepted: 11.10.2021, Online Yayınlanma / Published Online: 25.12.2021)

\begin{abstract}
Anahtar Kelimeler
Bayesci Yaklaşım,

Tip II Regresyon,

Bayes Regresyon,

Ölçüm Hatalı Modeller

İstatistiksel Modelleme
\end{abstract}

\begin{abstract}
Özet: Bu çalışmanın amacı Bayes Tip II regresyon tekniğinin performansını incelemektir. Bu amaçla gerçek bir veri seti üzerinde Bayes yaklaşımı yardımı ile basit doğrusal regresyon ve açıortay regresyon denklemleri hesaplanmıștır. Daha önceki çalışmalarda Tip II regresyon teknikleri arasında en iyi performansı sergileyen tekniğin açıortay tekniği olarak belirtilmesinden dolayı mevcut veri seti için sırasıyla X ve Y değişkenleri bağımlı değişken olarak ele alınarak regresyon denklemleri elde edilmiş, daha sonra elde edilen bu iki regresyon denkleminin açıortayı alınarak Bayes açıortay denklemi hesaplanmıștır. Önsel ve mevcut bilgi verisine dayalı sonsal dağılımları elde etmek amacıyla farklı örneklem hacimlerinden yararlanılmış ve Bayes regresyon denklemlerinin performansları HKO kriterine göre karşılaştırılmıştır. Araştırma bulgularına göre $n=100$ ve $n=30$ birimlik örneklemlerde Bayes açırtay tekniğinin performansının daha düşük HKO değerine sahip olduğu, dolayısıyla mevcut veri setine ait bu örneklem hacimleri için en iyi performansı sergilediği belirlenmiștir.
\end{abstract}

\section{Bayesian Bisector Regression Technique and an Application}

\section{Keywords}

Bayesian Approaches, Type II Regression, Bayesian Regression, Measurement Error Models Statistical Modeling

\begin{abstract}
The purpose of this study is to examine the performance of Bayesian Type II regression Analysis. With this purpose, simple linear regression and bisector regression equations are calculated by the help of Bayesian approach on a real data set. Because in the earlier studies its mentioned that the best technique among Type II regression techniques is the Bisector regression technique, regression equations are obtained by considering the $\mathrm{X}$ and $\mathrm{Y}$ variables as the dependent variable respectively and then the Bayesian Bisector equation is calculated by bisecting these two regression lines. Different sample sizes are considered to obtain the posterior distribution based on prior and likelihood information and then the performances of Bayesian regression equations are compared according to MSE criteria. The results of the study indicates that performance of Bayesian bisector technique has the minimum MSE for the sample sizes $n=100$ and $n=30$ which means that the performance of Bayesian bisector technique is the best for these sample sizes for the related data set.
\end{abstract}

\section{Giriş}

Bayesci yaklaşımın ilk temeli, İngiltere Tunbridge Wells'de yaşayan, bir rahip ve matematikçi olan Thomas Bayes tarafından düşünülmüş ve ölümünden 2 yıl sonra (1963) arkadaşı Richard Price' in Bayes' in çalışma kâğıtlarını bulması ve ardından yayınladığı bir makale olan "An Essay Towards Solving a Problem in the Doctrine of Chances" ile ortaya konmuştur [1].

Bayesci yaklaşımın özü, ele alınan bir çalışmada, konu ile ilgili gerçekleşen tüm bilginin analize dahil edilmesine dayanmaktadır. Bu yaklaşımda parametre, olasılık dağılımına sahip bir rasgele değişken olarak kabul edilmekte ve parametre ile ilgili çıkarsama, önsel bilgi ile mevcut bilgi birleştirilerek oluşturulan sonsal dağılım aracılığı ile yapılmaktadır. Bununla birlikte klasik yaklaşımda ise parametre bilinmeyen bir sabit olarak kabul edilerek, parametre tahmini sadece mevcut veriler ile yapılmaktadır [2].

Ayrıca bu yaklaşımın diğer bir önemli unsuru ise küçük örneklem hacimlerinde yapılan parametre tahminlerinde klasik yaklaşımlara göre daha iyi sonuçlar vermesidir. Klasik yaklaşımda zaman ve maliyet tasarrufu sağlamak amacıyla daha küçük 
örneklemler tercih edilirken parametre tahminleri güvenilirliğini yitirebilir ancak Bayesci yaklaşımda küçük örneklemler ile güvenilir sonuçlar elde etmek mümkündür [3].

Kısaca Bayes yaklaşımı, aslı Bayes Teoremine dayandırılarak yapılandırılmış bir yaklaşım sistemidir. Bayes teoremi, olasılık kuramı içinde incelenen önemli bir konudur. Bu teorem bir rasgele değişken için olasılık dağılımı içinde koşullu olasılıklar ile marjinal olasılıklar arasındaki ilişkiyi gösterir [4]. İfade edilen tüm bu özellikler klasik yaklaşım yerine Bayesci yaklaşımın kullanılması için önemli bir unsur oluşturmaktadır.

Tip II Regresyon tekniklerinin kullanılmasındaki amaç, bağımlı ve bağımsız değişkenlerin ölçümüne ilişkin oluşabilecek tüm ölçüm hatalarını analize dahil ederek bir model oluşturabilmektir. Günümüzde kullanılan klasik regresyon tekniklerinde bağımsız değişkenlerden kaynaklanabilecek hatalar göz ardı edilerek sadece bağıml değişken(ler)den kaynaklanan hatalar ile modeller oluşturulmaktadır. Ancak günlük hayatta bağımsız değişkenlerin de ölçüm hataları içerdiği bilinmektedir [5,6]. Bu nedenle klasik regresyon ile oluşturulan modellere kıyasla her iki ölçüm hatasını da içeren Tip II Regresyon tekniğinin kullanılması daha uygun olacaktır.

Bu çalışmada ise, Tip II regresyon tekniklerinden biri olan EKK-Açıortay tekniğine farklı bir bakış açısı getirilerek, parametre tahminleri EKK tekniği yerine Bayes yaklaşımı ile yapılarak Bayes-Açıortay tekniği ile regresyon denklemleri oluşturulacaktır. Ayrıca ilk defa kullanılan bu tekniğin performansı HKO kriterlerine göre değerlendirilecektir.

\section{Materyal ve Metot}

\subsection{Regresyon Analizi}

Regresyon analizi, değişkenler arasındaki neden sonuç ilişskisini bağımlı ve bağımsız değişkenler aracılığı ile açıklamaktadır. Regresyon analizi uygulamalarında bir bağımlı ve bir bağımsız değişken bulunması durumunda basit regresyon modeli, bir bağımlı değişken ve birçok bağımsız değişken bulunması durumunda ise çoklu regresyon modeli kullanılmaktadır [7].

Kurulan bir matematiksel regresyon modelinin doğrusal olup olmamasına göre farklı varsayımlar bulunmaktadır. Doğrusal regresyon modelleri bağımlı ve bağımsız değişken fonksiyonlarının aralarındaki ilişkinin doğrusal olması durumunda kullanılmaktadır [7]. Bu varsayımlar altında kurulan modelin parametre tahminlerine dair çeşitli yöntemler geliştirilmiştir. Bu yöntemler, en çok olabilirlik tahmin edicisi (EÇO), en küçük kareler tahmin edicisi (EKK), momentler tahin edicisi ve Bayesci tahmindir [8].

Buna ek olarak, Regresyon teknikleri, sadece bağımlı değişkenin değerinin kestirilmesinde ortaya çıkabilecek hatanın dikkate alınması veya ele alınacak olan tüm değişkenlerin elde edilmesinde oluşabilecek hataların dikkate alınması bakımından incelendiğinde Tip I ve Tip II regresyon tekniği olarak iki bölüme ayrılmaktadır [5].

Tip II Regresyon tekniğinde hata, Saraçlı (2008) tarafından yapılan çalışmada şu şekilde açıklanmıştır; “Tip II regresyon tekniklerinde genel olarak minimize edilmek istenen hata, gerçek değerlerden $\varepsilon$ ve $\delta$ büyüklüklerinde, çeşitli ölçüm hatası sebepleri ile yanlış ölçülmüş olan $x_{i}$ ve $y_{i}$ gözlem değerlerinin, tahmin edilmek istenen regresyon doğrusu üzerinde yer alan tahmini değerlerine olan dik ya da belirli bir açı ile olan uzaklıklarının karesidir."

\subsubsection{En Küçük Kareler (EKK) Açıortay Tekniği}

Bu teknik, sırası ile $Y$ ve $X$ değişkenlerini bağımlı ve bağımsız değișken olarak dikkate alarak iki ayrı regresyon doğrusunun açıortay doğrusunu elde ederek çözümlemeyi gerçekleştirir. Elde edilen bu açıortay doğrusu hem X hem de Y'deki hataları dikkate aldığından klasik EKK tekniğinden ayrılarak Tip II Regresyon tekniği olarak adlandırılır [9]. Saraçlı (2008) çalışmasında, Tip II Regresyon teknikleri arasında EKK-Açıortay tekniğinin diğer tekniklere göre daha iyi bir sonuç verdiğini ortaya koymuştur.

$\operatorname{EKK}(X \mid Y)$ regresyon doğrusu için elde edilen eğim katsayısı $\hat{\beta}_{1}$ ve $\operatorname{EKK}(Y \mid X)$ regresyon doğrusu için elde edilen eğim katsayısı $\hat{\beta}_{2}$ olmak üzere, EKK-Açıortay doğrusuna ait eğim katsayısı, sabit katsayı ve bu katsayılara ilişkin varyans ve kovaryanslar Eşitlik (1)(4)'de verildiği gibi hesaplanabilir [9].

$$
\begin{gathered}
\hat{\beta}_{1 A O}=\left(\hat{\beta}_{1}+\hat{\beta}_{2}\right)^{-1}\left[\hat{\beta}_{1} \hat{\beta}_{2}-1\right. \\
\left.+\sqrt{\left(1+\hat{\beta}_{1}{ }^{2}\right)\left(1+\hat{\beta}_{2}{ }^{2}\right)}\right] \\
\hat{\beta}_{0 A O}=\bar{y}-\hat{\beta}_{0 A 1} \bar{x} \\
=\frac{\operatorname{Var}\left(\hat{\beta}_{A O}\right)}{\left(\hat{\beta}_{1}+\hat{\beta}_{2}\right)^{2}\left(1+\hat{\beta}_{1}{ }^{2}\right)\left(1+\hat{\beta}_{2}{ }^{2}\right)}[(1 \\
\left.+\hat{\beta}_{2}{ }^{2}\right)^{2} \operatorname{Var}^{2}\left(\hat{\beta}_{1}\right) \\
\left.\left.+2{ }^{\left(1+\hat{\beta}_{1}{ }^{2}\right)(1}+\hat{\beta}_{2}{ }^{2}\right) \operatorname{Cov}\left(\hat{\beta}_{1}, \hat{\beta}_{2}\right)+\left(1+\hat{\beta}_{1}{ }^{2}\right)^{2} \operatorname{Var}\left(\hat{\beta}_{2}\right)\right]
\end{gathered}
$$




$$
\begin{aligned}
\operatorname{Cov}\left(\hat{\beta}_{1}, \hat{\beta}_{2}\right)= & \left(\hat{\beta}_{1} S_{x x}^{2}\right)^{-1}\left\{\sum _ { i = 1 } ^ { n } ( x _ { i } - \overline { x } ) \left(y_{i}\right.\right. \\
& -\bar{y})\left[y_{i}-\bar{y}-\hat{\beta}_{1}\left(x_{i}-\bar{x}\right)\right]\left[y_{i}\right. \\
& \left.\left.-\bar{y}-\hat{\beta}_{2}\left(x_{i}-\bar{x}\right)\right]\right\}
\end{aligned}
$$

\subsubsection{Bilgi Veren Önsel Dağılım Kullanılarak Uygulanan Bayes Regresyon Tekniği}

Bilgi veren önsel dağılım ile analiz yapılması halinde araștırmacı çoğu zaman tahmin edilmek istenen parametreye dair bilgiye sahip değildir. Ancak araștırmacının önsel bilgisi daha önceki yapılan araștırmalardan ve teorik bilgisine dayalı olarak oluşturulabilmektedir Bu aşamada önsel bilgiyi en iyi şekilde yansıtan ve benzerlik fonksiyonu ile matematiksel olarak daha kolay bir șekilde birleșebilen dağılımlar kullanmak mümkündür. Birçok durumda, "Doğal Eşlenik Önsel Dağılımlar" bu özellikleri sağlayacak yapıya sahiptir. Doğal Eșlenik Önsel Dağılım ile olabilirlik fonksiyonunun birleşmesi ile ortaya çıkan sonsal dağılım, Doğal Eşlenik Önsel ile aynı dağılıma sahip olacaktır [10].

Bu bölümde doğal eşlenik önsel dağılım kullanılarak, bilgi veren önsel dağılım yardımı ile sonsal dağılım elde edilecektir. Bayes teoremi doğrusal regresyon modeline uyarlanmadan önce kısaca aşağıdaki gibi yazılı olarak ifade edilebilir.

$$
\begin{aligned}
\text { sonsal dağılım } & \propto \text { olabilirlik fonksiyonu } \\
& \times \text { önsel dağılım }
\end{aligned}
$$

Yukarıda ifade edilen toreme dayanarak regresyon modelinin oluşturulabilmesi için öncelikle önsel dağılım oluşturulmalı ve daha sonra olabilirlik fonkisyonu ile birleștirilerek sonsal dağılım elde edilmelidir. $\mathrm{Bu}$ aşamada elde edilen Bayes ilkeleri Lineer Doğrusal Regresyon modeline uyarlanarak Lineer Bayes Regresyon Modeli elde edilebilmektedir.

$$
y=X \beta+\varepsilon
$$

Lineer Regresyon modeli olan Eşitlik (6)'ya göre, $y$, $(\mathrm{T} \times 1)$ büyüklüğünde bağımlı değişkenlerin gözlem vektörü, $X, \mathrm{~K}$ açıklayıcı değișkenleri üzerinde $(\mathrm{T} \times \mathrm{K})$ boyutlu bir gözlem matrisi, $\varepsilon, \varepsilon \sim N\left(0, \sigma^{2}\right)$ dağılıma sahip $(\mathrm{T} \times 1)$ boyutunda bir hata vektörü ve $\beta$ ve $\sigma$ hakkında bilgi edinmek istediğimiz parametreleri ifade etmektedir. Burada $\theta=\left(\beta^{\prime}, \sigma\right)^{\prime}$ olmak üzere Eşitlik (5) yardımı ile Eşitlik (7) elde edilebilir [10].

$$
g(\beta, \sigma \mid y) \propto l(\beta, \sigma \mid y) g(\beta, \sigma)
$$

Bayesci yaklaşım için olabilirlik fonksiyonu Eşitlik (8)'de belirtildiği gibi yazılabilir [11].

$$
\begin{aligned}
l(\beta, \sigma \mid y) \propto & \frac{1}{(2 \pi)^{T / 2}} \frac{1}{\sigma^{T}} \exp \left\{-\frac{1}{2 \sigma^{2}}[(y\right. \\
& \left.\left.-X \beta)^{\prime}(y-X \beta)\right]\right\}
\end{aligned}
$$

Burada $\left(b^{\prime}, \hat{\sigma}^{2}\right)$ yeterli istatistik olmak üzere Eşitlik (9) yazilabilir.

$$
\begin{gathered}
\left.b=\left(X^{\prime} X\right)^{\prime} X^{\prime} y, \hat{\sigma}^{2}=(y-X b)^{\prime}(y-X b) / v\right), \\
v=T-K
\end{gathered}
$$

Eşitlik (9)'da belirtilen ifadeler EKK yöntemi ile elde edilen parametre tahmin edicileridir. Yukarıdaki denklemler kullanılarak elde edilecek olan $\bar{\beta}, \bar{v}$ ve $\bar{s}^{2}$ ifadeleri önsel dağılıma ilişkin tahmin edicileri $\overline{\bar{\beta}}$, $\bar{v}$ ve $\overline{\bar{s}}^{2}$ ifadeleri ise sonsal dağılıma ilişkin tahmin edicileri göstermektedir [12; 13].

Bayesci yaklaşım kullanılarak önsel dağılıma ilişkin $\beta$ ve $\sigma$ parametresinin ortalama ve varyans değerleri aşağıdaki eşitlikler ile elde edilir.

$$
\begin{gathered}
E[\beta \mid \sigma]=E[\beta]=\bar{\beta}, \operatorname{cov}[\beta \mid \sigma]=A^{-1} \sigma^{2}, \\
A=\left(X^{\prime} X\right)^{-1} X^{\prime} \\
E[\sigma]=\frac{\Gamma[(\bar{v}-1) / 2]}{\Gamma(\bar{v} / 2)}\left(\frac{\bar{v}}{2}\right)^{1 / 2} \bar{s}, \\
E\left[\sigma^{2}\right]=\frac{\bar{v} \bar{s}^{2}}{\bar{v}-2}
\end{gathered}
$$

$A$ simetrik bir matris ve $A=A^{1 / 2} A^{1 / 2}$ olmak üzere Eşitlik (12) yazılırsa;

$$
w=\left(\begin{array}{c}
A^{1 / 2} \bar{\beta} \\
y
\end{array}\right), W=\left(\begin{array}{c}
A^{1 / 2} \\
X
\end{array}\right)
$$

Olmak üzere;

Parametre tahmincileri;

$$
\begin{aligned}
& \overline{\bar{\beta}}=\left(W^{\prime} W\right)^{-1} W^{\prime} w \\
& =\left(A+X^{\prime} X\right)^{-1}(A \bar{\beta} \\
& \left.+X^{\prime} X b\right) \\
& \overline{\bar{v}} \overline{\bar{S}}^{2}=\bar{v} \bar{s}^{2}+(w-W \overline{\bar{\beta}})^{\prime}(w-W \overline{\bar{\beta}}) \\
& =\bar{v} \bar{s}^{2}+y^{\prime} y+\bar{\beta}^{\prime} A \bar{\beta} \\
& \text { - } \overline{\bar{\beta}}^{\prime}\left(X^{\prime} X\right) \overline{\bar{\beta}} \\
& \overline{\bar{v}}=T+\bar{v}
\end{aligned}
$$

ve Bayes regresyon modeli;

$$
\begin{aligned}
& g(\beta, \sigma \mid y) \\
& \propto \sigma^{-\bar{v}-K-1} \exp \left\{-\frac{1}{2 \sigma^{2}}\left[\bar{v} \bar{s}^{2}\right.\right. \\
& +(w-W \overline{\bar{\beta}})^{\prime}(w-W \overline{\bar{\beta}})+(\beta \\
& \left.\left.-\overline{\bar{\beta}})^{\prime} W^{\prime} W(\beta-\overline{\bar{\beta}})\right]\right\}
\end{aligned}
$$

$$
\begin{gathered}
g(\beta, \sigma \mid y) \\
\propto \sigma^{-K} \exp \left[-\frac{1}{2 \sigma^{2}}(\beta-\overline{\bar{\beta}})^{\prime}\left(A+X^{\prime} X\right)(\beta\right. \\
-\overline{\bar{\beta}})] \cdot \sigma^{-(\overline{\bar{v}}+1)} \exp \left(-\frac{\overline{\bar{v}} \overline{\bar{s}}^{2}}{2 \sigma^{2}}\right)
\end{gathered}
$$




$$
g(\beta, \sigma \mid y) \propto g(\beta \mid \sigma, y) \cdot g(\sigma \mid y)
$$

elde edilir. Burada $\beta$ parametresi için koșullu yoğunluk fonksiyonu $\overline{\bar{\beta}}$ ortalamal, $\sigma^{2}\left(A+X^{\prime} X\right)^{1}$ kovaryans matrisi ile "çok değişkenli normal" dağılıma sahiptir ve $\sigma$ parametresi için de marjinal sonsal yoğunluk fonksiyonu $\overline{\bar{v}}$ ve $\overline{\bar{s}}^{2}$ parametreleri ile "TersGamma" dağılımına uymaktadır [10].

Bu çalışmada, gerçek veriler üzerinde Bayes-Açıortay tekniği ile farklı örneklem hacimlerinde regresyon modeli oluşturularak, HKO kriterine göre performansının değerlendirilmesi amaçlanmıştır. $\mathrm{Bu}$ amaçla, Saraçlı ve Çelik'in (2012) çalışmalarında [14] kullandığı, Van Yüzüncüyıl Araştırma Hastanesi Acil Servisine gelen 100 hastadan derlenen koltuk altı (aksiller) ve kulaktan ateş ölçer aletleri yardımı ile elde edilen gerçek veriler kullanılmıştır. Regresyon çözümlemesi yapılırken $\mathrm{X}$ değişsenine ait terimler koltuk altı ve $\mathrm{Y}$ değişkenine ait terimler ise kulaktan elde edilen veriler olarak kullanılmıștır. Verilerin analizi gerçekleştirilmeden önce ise normal dağılıma uygunluğu Kolmogorov-Smirnov testi ile incelenmiştir. Test sonucunda verilerin normal dağllıma uygunluk gösterdiği belirlenmiştir.

Bayes tekniği ile elde edilen Açıortay regresyon denklemlerinin HKO değerlerinin hesaplanması amacı ile sırasıyla örneklem hacimleri 100 ve 30 olarak seçilmiştir. 100 birimlik veri seti, 30 önsel bilgi verisi ve 70 birimlik mevcut veri, ilk 30 gözlem değeri ise 5$25,10-20$ ve $15-15$ şeklinde önsel bilgi verisi ve mevcut veri olarak ayrilarak regresyon modelleri oluşturulmuştur. Çalışmada önsel dağılımın belirlenmesi aşamasında ise, mevcut veri setinin dağılımının normal olması ve matematiksel açıdan regresyon denkleminin oluşturulmasında uygunluk sağlaması sebebi ile önsel dağllım olarak "Doğal Eşlenik Önsel Dağılım" seçilmiştir. Önsel dağılıma ilişkin $\beta$ parametresinin ortalama ve kovaryans değerleri Eşitlik (19) ile, $\sigma$ parametresine ait ortalama ve varyans değerleri ise Eşitlik (20) ile hesaplanmıştır.

$$
\begin{gathered}
E[\beta \mid \sigma]=E[\beta]=\bar{\beta}, \operatorname{cov}[\beta \mid \sigma] \\
=A^{-1} \sigma^{2}, \\
A=\left(X^{\prime} X\right)^{-1} X^{\prime} \\
E[\sigma]=\frac{\Gamma[(\bar{v}-1) / 2]}{\Gamma(\bar{v} / 2)}\left(\frac{\bar{v}}{2}\right)^{1 / 2} \bar{s}, \\
E\left[\sigma^{2}\right]=\frac{\bar{v} \bar{s}^{2}}{\bar{v}-2}
\end{gathered}
$$

Burada $\bar{\beta}$ ve $\bar{s}$ değerleri, önsel verilere ait EKK tekniği ile elde edilen tahmin değerleri ve $\sigma^{2}$, önsel verilerle oluşturulan regresyon denklemine ait hata değerini ifade etmektedir.

Çalışmada önsel dağılım için parametre değerlerine ait ortalama ve varyans değerlerinin belirlenmesinin ardından sonsal dağılımın oluşturulabilmesi amacı ile
STATA paket programı kullanılmıştır. Kullanılan programda, önsel verilere ait bilgiler ve mevcut veri bilgisi birleştirilerek Bayes(Y/X) ve Bayes(X/Y) doğruları hesaplanmıștır.

Önsel verilere ait bilgiler için ilk olarak , bilgi içeren önsel dağılım ile lineer Bayes Regresyon modelinin oluşturulması kısmında belirtildiği üzere $\beta$ parametresinin dağılımı normal dağılım, $\sigma$ parametresinin dağılımı ise ters-gamma dağılımı seçilerek bu iki parametre değeri için de hesaplanan ortalama ve varyans değerleri dikkate alınmış, ikinci olarak da $\mathrm{X}$ ve $\mathrm{Y}$ değişkenleri için önsel verilerin ortalama ve varyans değerleri hesaplanarak çözümleme gerçekleştirilmiştir.

Son olarak elde edilen önsel bilgi kullanılarak mevcut verilere bağlı olarak Bayes Regresyon denklemi elde edilmiştir.

Bayes tekniği ile elde edilen Açıortay denklemini oluşturmak amacı ile Bayes(Y/X) (Y bağımlı, X bağımsız değişken) ve Bayes(X/Y) (X bağımlı, Y bağımsız değişken) doğruları için sabit katsayı ve eğim katsayısı değerleri Eşitlik (21)' de belirtildiği gibi hesaplanmiştır.

$$
\begin{gathered}
\hat{\beta}_{1}=\frac{n \sum x_{\mathrm{i}} y_{i}-\sum\left(x_{\mathrm{i}}\right) \sum\left(y_{i}\right)}{n \sum x_{\mathrm{i}}^{2}-\sum\left(x_{\mathrm{i}}\right)^{2}}, \\
\hat{\beta}_{0}=\bar{y}-\hat{\beta}_{1} \bar{x}
\end{gathered}
$$

Oluşturulan Bayes(Y/X) ve Bayes(X/Y) regresyon doğrularının eğim katsayıları sırası ile $\hat{\beta}_{1}$ ve $\hat{\beta}_{2}$ olarak alınarak Bayes-Açıortay regresyon doğrusunun eğim katsayısı ve sabit katsayı Eşitlik (1), (2)'de belirtildiği gibi hesaplanmış olup bu katsayılara bağlı BayesAçıortay regresyon denklemi Eşitlik (22)'de belirtildiği gibi hesaplanmıştır.

$$
y_{i B A Y E S A O}=\hat{\beta}_{0}+\hat{\beta}_{A O} \bar{x}_{i}
$$

Elde edilen Bayes(Y/X), Bayes(X/Y) ve Bayes-Açırtay regresyon denklemlerinin mevcut veri seti için sergiledikleri performansları ise Eşitlik (25)'de verilen HKO kriteri yardımıyla değerlendirilmiştir.

$$
H K O=\frac{\sum\left(Y_{i}-\hat{Y}_{i}\right)^{2}}{n-k}
$$

\section{Bulgular}

Farklı örneklem hacimlerinde, önsel bilgi verisi ve mevcut veri hacimlerinin farklı olarak seçilmesi ile oluşturulan regresyon doğruları için hesaplanan önsel dağılımlara ait paremetre değerlerinin ortalama ve varyans değerleri Tablo 1. ve 3'de verilmiştir. Ayrıca Bayes(Y/X), Bayes(X/Y) ve Bayes Açıortay regresyon tekniklerine ilişkin sabit katsayı, eğim katsayısı ve HKO değerleri Tablo 1. Ve 3'de belirtirlmiştir. 
Tablo 1. $n=100$ iken Bayes $(Y / X)$ ve Bayes(X/Y) regresyon doğruları için hesaplanan önsel dağılıma ait parametrelerin ortalama ve varyans değerleri.

\begin{tabular}{|c|c|c|c|c|c|}
\hline & & \multicolumn{2}{|c|}{$\beta$} & \multicolumn{2}{|c|}{$\sigma$} \\
\hline & & Ortalama & Varyans & Ortalama & Varyans \\
\hline \multirow{2}{*}{$30 *$} & Bayes(Y/X) & 0,968 & 0,0035 & 0,1172 & 0,014 \\
\hline & Bayes (X/Y) & 0,938 & 0,0031 & 0,1126 & 0,013 \\
\hline \multirow{2}{*}{$40 *$} & Bayes(Y/X) & 1,004 & 0,0019 & 0,107 & 0,0116 \\
\hline & Bayes $(\mathrm{X} / \mathrm{Y})$ & 0,929 & 0,0016 & 0,102 & 0,01005 \\
\hline \multirow{2}{*}{$50 *$} & Bayes $(\mathrm{Y} / \mathrm{X})$ & 0,981 & 0,0014 & 0,1016 & 0,01043 \\
\hline & Bayes $(\mathrm{X} / \mathrm{Y})$ & 0,953 & 0,0014 & 0,1016 & 0,01043 \\
\hline
\end{tabular}

* Önsel bilgi verisi için örneklem hacmi

Tablo 2. $n=100$ iken Bayes-Açıortay, Bayes(Y/X) ve Bayes(X/Y) regresyon teknikleri için hesaplanan sabit katsayı, eğim katsayısı ve HKO değerleri.

\begin{tabular}{lrrlrrrrrc}
\hline & \multicolumn{3}{c}{$30^{*}-70^{* *}$} & \multicolumn{3}{c}{$40^{*}-60^{* *}$} & \multicolumn{3}{c}{$50^{*}-50^{* *}$} \\
\cline { 2 - 10 } & $\hat{\beta}_{0}$ & $\hat{\beta}_{1}$ & HKO & $\hat{\beta}_{0}$ & $\hat{\beta}_{1}$ & HKO & $\hat{\beta}_{0}$ & $\hat{\beta}_{1}$ & HKO \\
\hline Bayes $_{\mathrm{Y} \mid \mathrm{X})}$ & 0,944 & 0,976 & 0,009651 & 0,993 & 0,969 & 0,008491 & 0,972 & 0,961 & 0,009083 \\
\hline Bayes $_{\mathrm{X} \mid \mathrm{Y})}$ & 0,911 & 0,979 & 0,009503 & 0,917 & 0,979 & 0,009126 & 0,943 & 0,978 & 0,009829 \\
\hline Bayes & 0,761 & 0,975 & 0,008408 & 0,798 & 0,974 & 0,008404 & 0,798 & 0,974 & 0,008404 \\
\hline
\end{tabular}

* Önsel bilgi verisi için örneklem hacmi

** Mevcut veri seti için örneklem hacmi

Tablo 1. ve Tablo 2. incelendiğinde, 100 birimlik veri seti 30 birimlik önsel bilgi ve 70 birimlik mevcut bilgi verisi olarak ayrıldığında, Bayes(Y/X) tekniği için önsel verilere ait $\beta$ 'nın dağılımı $\operatorname{Normal}(0,968$, 0,0035), $\sigma$ 'nın dağılımı Ters-Gamma(0,1172, 0,014) ve $X$ bağımsız değişkeninin dağılımı Normal(37,06,0,1251) iken sonsal dağılımın HKO değeri 0,009651, Bayes(X/Y) tekniği için önsel verilere ait $\beta$ 'nın dağılımı $\operatorname{Normal}(0,938,0,0031)$, $\sigma$ 'nın dağılımı Ters-Gamma(0,1126, 0,013) ve Y bağımsız değişkeninin dağılımı $\operatorname{Normal}(36,84$, 0,1291 ) iken sonsal dağılımın HKO değeri 0,009503 ve Bayes(Y/X) ve Bayes(X/Y) teknikleri ile oluşturulan regresyon doğrularının açıortayı alınarak elde edilen Bayes-Açıortay tekniğinin HKO değeri 0,008408 olarak hesaplanmıştır.

100 birimlik veri seti 40 birimlik önsel bilgi verisi ve 60 birimlik mevcut veri olarak ayrıldığında, Bayes(Y/X) tekniği ile hesaplanan önsel verilere ait $\beta$ 'nın dağılımı Normal(1,004, 0,0019), $\sigma$ 'nın dağılımı Ters-Gamma(0,107, 0,0116) ve $X$ bağımsız değişkeninin dağılımı Normal(37,15, 0,1415) iken sonsal dağılıma ait HKO değeri 0,008491, Bayes(X/Y) tekniği için önsel verilere ait $\beta$ 'nın dağılımı Normal $(0,929,0,0016), \sigma$ 'nın dağılımı TersGamma(0,102, 0,01005) ve Y bağımsız değişkeninin dağılımı Normal(36,94, 0,1530) iken sonsal dağılımın HKO değeri 0,009126 olarak hesaplanmıștır. Ayrıca Bayes(Y/X) ve Bayes(X/Y) tekniği ile oluşturulan regresyon doğrularının açırtayı alınarak oluşturulan Bayes-Açıortay tekniğinin HKO değeri 0,008404 olarak hesaplanmıştır.

100 birimlik veri seti 50 birimlik önsel bilgi verisi ve 50 birimlik mevcut veri olarak ayrıldığında ise Bayes $(\mathrm{Y} / \mathrm{X})$ tekniği için önsel verilere ait $\beta$ 'nın dağılımı Normal $(0,981,0,0014)$, $\sigma$ 'nın dağılımı TersGamma(0,1016, 0,01043) ve X bağımsız değişkeninin dağılımı Normal(37,11, 0,1457) iken sonsal dağılımın HKO değeri 0,009083, Bayes(X/Y) tekniği için önsel verilere ait $\beta$ 'nın dağılımı $\operatorname{Normal}(0,953,0,0014)$, $\sigma$ 'nın dağılımı Ters-Gamma(0,1016, 0,01043$)$ ve Y bağımsız değişkeninin dağılımı Normal(36,92, 0,1457) iken sonsal dağılımın HKO değeri 0,009829 olarak hesaplanmıștır. Buna ek olarak Bayes(Y/X) ve Bayes(X/Y) tekniği ile elde edilen regresyon doğrularının açırtayı alınarak oluşturulan BayesAçıortay tekniğinin HKO değeri 0,008404 olarak hesaplanmıştır.

Tablo 2.'ye göre 100 birimlik veri seti 40 birimlik önsel bilgi verisi ve 60 birimlik mevcut veri olarak ayrıldığında, elde edilen Bayes(Y/X) ve Bayes(X/Y) tekniklerinin daha düşük HKO değerlerine sahip olduğu gözlemlenmiștir. Ayrıca 100 birimlik veri seti $40 *-60 * *$ ve $50 *-50 * *$ olarak ayrıldığında BayesAçıortay tekniğinin HKO değerlerinin eşit ve $30 *-70 * *$ alınarak oluşturulan Bayes-Açıortay tekniğine göre daha az hataya sahip oldukları görülmektedir. Genel olarak HKO değerleri incelendiğinde ise BayesAçıortay tekniğinin HKO değerlerinin Bayes(Y/X) ve Bayes(X/Y) teknikleri için hesaplanan HKO değerlerine göre daha düşük olduğu tespit edilmiştir.

Tablo 3. ve Tablo 4.'e göre, 30 birimlik veri seti 5 birimlik önsel bilgi verisi ve 25 birimlik mevcut veri olarak ayrıldığına önsel bilgi verisine ait $\beta$ parametresinin dağılımı Normal(0,696, 0,0087), $\sigma$ parametresinin dağılımı Ters-Gamma(0,3069, 0,015) ve $X$ bağımsız değişkeninin dağılımı Normal(36,94, 0,1144) iken Bayes(Y/X) tekniğinin HKO değeri 0,013328 olarak hesaplanmıştır. Önsel bilgi verisine ait $\beta$ parametresinin dağılımı $\operatorname{Normal}(1,363,0,0342)$, $\sigma$ parametresinin dağılımı Ters-Gamma(0,4341, 0,03) ve $Y$ bağımsız değişkeninin dağılımı $\operatorname{Normal}(36,66$, 0,0584) iken ise Bayes(X/Y) tekniğinin HKO değeri 0,012726 olarak hesaplanmıştır. Ayrıca Bayes(Y/X) ve 
Tablo 3. $n=30$ iken Bayes(Y/X) ve Bayes(X/Y) regresyon doğruları için hesaplanan önsel dağılıma ait parametrelerin ortalama ve varyans değerleri.

\begin{tabular}{llllll}
\hline & & \multicolumn{2}{c}{$\beta$} & & \multicolumn{2}{c}{$\sigma$} \\
\cline { 3 - 6 } & & Ortalama & Varyans & Ortalama & Varyans \\
\hline \multirow{2}{*}{$5^{*}$} & Bayes(Y/X) & 0,696 & 0,0087 & 0,3069 & 0,015 \\
& Bayes(X/Y) & 1,363 & 0,0342 & 0,4341 & 0,03 \\
\multirow{2}{*}{$10^{*}$} & Bayes(Y/X) & 0,865 & 0,0126 & 0,1162 & 0,0147 \\
& Bayes(X/Y) & 1,019 & 0,0175 & 0,1263 & 0,0173 \\
\multirow{2}{*}{$15^{*}$} & Bayes(Y/X) & 0,885 & 0,0031 & 0,2985 & 0,00945 \\
& Bayes(X/Y) & 1,072 & 0,0046 & 0,3338 & 0,0118 \\
\hline
\end{tabular}

* Önsel bilgi verisi için örneklem hacmi

Tablo 4. $n=30$ iken Bayes-Açıortay, Bayes(Y/X) ve Bayes(X/Y) regresyon teknikleri için hesaplanan sabit katsayı, eğim katsayısı ve HKO değerleri.

\begin{tabular}{lrrrrrrrrc}
\hline & $5^{*}-25^{* *}$ & \multicolumn{1}{c}{$10^{*}-20^{* *}$} & \multicolumn{3}{c}{$15^{*}-15^{* *}$} \\
& $\hat{\beta}_{0}$ & $\hat{\beta}_{1}$ & HKO & $\hat{\beta}_{0}$ & $\hat{\beta}_{1}$ & HKO & $\hat{\beta}_{0}$ & $\hat{\beta}_{1}$ & HKO \\
\hline Bayes $(\mathrm{Y} \mid \mathrm{X})$ & 0,621 & 0,978 & 0,013328 & 0,725 & 0,975 & 0,013033 & 0,864 & 0,973 & 0,019648 \\
\hline Bayes $(\mathrm{X} \mid \mathrm{Y})$ & 0,813 & 0,984 & 0,012726 & 0,796 & 0,984 & 0,012786 & 1,042 & 0,976 & 0,0163 \\
\hline BayesAO & 0,488 & 0,981 & 0,012802 & 0,543 & 0,979 & 0,012797 & 0,728 & 0,975 & 0,012785 \\
\hline
\end{tabular}

* Önsel bilgi verisi için örneklem hacmi

** Mevcut veri seti için örneklem hacmi

Bayes(X/Y) teknikleri ile elde edilen regresyon doğrularının açıortayı alınarak oluşturulan BayesAçıortay tekniğinin HKO değeri 0,012802 olarak hesaplanmıștır.

30 birimlik veri setinin 10 birimlik önsel bilgi verisi ve 20 birimlik mevcut veri olarak ayrıldı̆̆ durumda, önsel bilgi verisine ait $\beta$ parametresinin dağılımı Normal $(0,865,0,0126), \sigma$ parametresinin dağılımı Ters-Gamma(0,1162, 0,0147) ve $X$ bağımsız değişkeninin dağılımı Normal(37,02, 0,0876) iken Bayes(Y/X) tekniğine ait HKO değeri 0,013033 olarak hesaplanmiștır. Önsel bilgi verisine ait $\beta$ parametresinin dağılımı Normal(1,019, 0,0175), $\sigma$ parametresinin dağılımı Ters-Gamma(0,1263, 0,0173) ve $Y$ bağımsız değişkeninin dağılımı Normal(36,76, 0,0744) iken Bayes(X/Y) tekniğinin HKO değeri 0,012786 olarak hesaplanmıştır. Buna ek olarak Bayes(Y/X) ve Bayes(X/Y) tekniği ile oluşturulan regresyon doğrularının açıortayı alınarak oluşturulan Bayes-Açıortay tekniğinin HKO değerinin 0,012797 olduğu görülmektedir.

30 birimlik veri seti, 15 birimlik önsel bilgi verisi ve 15 birimlik mevcut veri olarak ayrıldığında ise, önsel bilgi verisine ait $\beta$ parametresinin dağılımı $\operatorname{Normal}(0,885$, 0,0031), $\sigma$ parametresinin dağılımı TersGamma(0,2985, 0,00945) ve X bağımsız değişkeninin dağılımı Normal(37,03, 0,1742) iken Bayes(Y/X) tekniğinin HKO değeri 0,019648 olarak hesaplanmıştır. Önsel bilgi verisine ait $\beta$ parametresinin dağılımı Normal(1,072, 0,0046), $\sigma$ parametresinin dağılımı Ters-Gamma(0,3338, 0,0118) ve $Y$ bağımsız değişkeninin dağılımı Normal $(36,75,0,1438)$ iken ise Bayes(X/Y) tekniğinin HKO değeri 0,0163 olarak hesaplanmıştır. Ayrıca Bayes-Açıortay regresyon tekniğinin HKO değerinin 0,012785 olduğu görülmektedir.

Tablo 4.'e göre, Bayes(Y/X) tekniği için hesaplanan HKO değerinin, 30 birimlik veri seti $10^{*}-20^{* *}$ şeklinde ayrıldığında daha düşük olduğu görülmektedir. Bayes(X/Y) tekniğinin HKO değeri ise 75 birimlik veri seti $5^{*}-25^{* *}$ şeklinde ayrıldığında daha düşük olduğu belirlenmiştir. Bayes-Açıortay tekniğinin HKO değerinin önsel bilgi verisinin örneklem hacmi arttıkça azaldığı ve 30 birimlik veri seti $5^{*}-25^{* *}$ şeklinde ayrıldığında en düşük HKO değerine sahip olduğu görülmektedir. Ayrıca 30 birimlik veri setinin $5^{*}-15^{* *}$ ve $10^{*}-20^{*}$ şeklinde ayrıldığ durumlarda Bayes(X/Y) tekniği için hesaplanan HKO değerinin Bayes(Y/X) ve Bayes-Açıortay tekniklerinin HKO değerine göre daha düşük olduğu görülmektedir. Buna ek olarak, 30 birimlik veri setinin $15^{*}-15^{* *}$ şeklinde ayrılması halinde Bayes-Açıortay tekniği için hesaplanan HKO değerinin Bayes(Y/X) ve Bayes(X/Y) tekniklerinin HKO değerlerine göre daha düşük olduğu belirlenmiştir.

\section{Tartışma ve Sonuç}

$\mathrm{Bu}$ çalışmada, Bayesci yaklaşım açıklanarak, bu yaklaşım aracılığı ile sadece bağımlı değișkenler değil, aynı zamanda bağımsız değişkenlerinin hatalarını da analize dahil eden Tip II regresyon tekniklerinden biri olan Açıortay tekniği kullanılarak parametre tahminleri yapılmış ve Bayes-Açıortay tekniği ortaya konmuştur. Yapılan analizlerde farklı örneklem hacimleri, bu örneklem hacimlerinde farklı önsel bilgi veri hacmi ve farklı mevcut veri hacimleri alınarak Bayes-Açıortay tekniğinin performansına ilișkin değerlendirmeler yapılmıştır. Çalıșmada elde edilen bulgular gerçek veri setinden elde edilmiş olup bir simülasyon yapılmamıștır.

Bayes-Açırtay tekniğinin performansının değerlendirilmesi amacı ile yapılan analizler sonucunda regresyon doğrularının HKO değerleri hesaplanmıştır. Elde edilen sonuçlar doğrultusunda Bayes-Açıortay tekniği için elde edilen HKO değerlerinin, 30 birimlik veri seti için $5^{*}-25^{* *}$ ve $10^{*}$ $20^{* *}$ olarak ayrilan örneklerle kurulan Bayes(X/Y) 
modeli hariç, Bayes(Y/X) ve Bayes(X/Y) regresyon doğruları için hesaplanan HKO değerlerine göre daha düşük olduğu ve performansının daha iyi oluğu gözlemlenmiştir. Daha önce yapılan araştırmalarda Bayes tekniğinin küçük örneklem hacimlerinde daha iyi sonuçlar verdiği tespit edilmiş olup yapılan bu çalışmada büyük örneklem hacminde $(n=100)$ tüm veri setleri için Bayes-Açıortay tekniğinin daha düşük HKO değerine sahip olduğu gözlemlenmiștir.

Çalışmada önsel bilgi ve mevcut verilerin örneklem hacimlerinin artırılıp azaltılması sonucunda her bir veri seti için hesaplanan regresyon doğrularının HKO değerlerine ilişkin genel olarak Bayes-Açıortay tekniğinin klasik tekniğe göre yakın veya daha iyi sonuçlar verdiği söylenebilmektedir. Bazı veri setlerinde önsel bilgi veri hacminin küçük olduğu ve mevcut veri hacminin daha büyük olduğu durumda HKO değerinin düşük olduğu, bazılarında ise önsel bilgi veri hacminin büyük, mevcut veri hacminin küçük olduğu durumlarda HKO değerinin düşük olduğu gözlemlenmiştir.

Genel olarak herhangi bir regresyon modeli oluşturmada gerekli varsayımların sağlanması halinde Tip I Regresyon tekniği kullanılmakta ve oluşturulan regresyon modeline ilişkin parametre tahmin etmede klasik yöntemler kullanılmaktadır. Fakat gerçekte elde edilen bağımsız değişkenlerden oluşabilecek hataların da analize dahil edilebilmesini sağlayan Tip II Regresyon tekniklerinin kullanılması yapılan analizlerde avantaj sağlamaktır. Tip II regresyon tekniklerinden biri olan Açırtay tekniğinde parametre tahmin yöntemi olarak EKK tekniği kullanılmaktadır. Bu çalışmada ise, EKK tekniği yerine, Bayes yaklaşımı aracılığıyla parametre tahmini yapılarak ilk defa Bayes-Açıortay tekniği ortaya konmuştur. Ayrıca ortaya konulan bu tekniğin literatüre önemli bir katkı sağlayacağı öngörülmektedir.

\section{Etik Beyanı}

Bu çalışma, Ece Özgören'in Sinan Saraçlı danışmanlığında Afyon Kocatepe Üniversitesi Fen Bilimleri Enstitüsünde tamamlanan yüksek lisans tezinden üretilmiş olmakla birlikte çalışmada "Yükseköğretim Kurumları Bilimsel Araştırma ve Yayın Etiği Yönergesi” kapsamında uyulması gerekli tüm kurallara uyulduğunu, bahsi geçen yönergenin "Bilimsel Araştırma ve Yayın Etiğine Aykırı Eylemler" başlığı altında belirtilen eylemlerden hiçbirinin gerçekleştirilmediğini taahhüt ederiz.

\section{Kaynakça}

[1] Stigler, S. M. 1983. Who Discovered Bayes's Theorem. The American Statistician, 37(4), 290296.
[2] Bolstad, W. M. 2007. Introduction to Bayesian Statistics. 2nd edition. Wiley - Interscience Hamilton, New Zealand, 463s.

[3] Avcı, E. 2012. Bayesci Sağkalım Analizi ve Meme Kanseri Verileri Üzerine Bir Uygulama. Mimar Sinan Güzel Sanatlar Üniversitesi, Fen Bilimleri Enstitüsü, Doktora 82s, Tezi, İstanbul.

[4] Altındağ, İ. 2015. Bayesci Doğrusal Olmayan Yapısal Eşitlik Modeli. Selçuk Üniversitesi, Fen Bilimleri Enstitüsü, Doktora Tezi,150s, Konya.

[5] Saraçlı, S. 2008. Ölçüm Hatalı Modellerde Doğrusal Regresyon Tekniklerinin Karşılaştırılması-Monte Carlo Simülasyon Çalışması. Eskișehir Osmangazi üniversitesi, Fen Bilimleri Enstitüsü, Doktora Tezi, 90s, Eskișehir.

[6] Özgören, E. 2019. Bayes Açıortay Regresyon Tekniği ve Bir Uygulama. Afyon Kocatepe Üniversitesi, Fen Bilimleri Enstitüsü, Yüksel Lisans Tezi, 87s, Afyonkarahisar.

[7] Çiftci, F. 2009. Regresyonda Alternatif Metotlar. Selçuk Üniversitesi, Fen Bilimleri Enstitüsü, Doktora Tezi, 103s, Konya.

[8] Çevik, M. 2009. Doğrusal Olmayan Bayesci Regresyon ve Yüksek Frekanslı Ses Sistemlerinde Bir Uygulama. Yıldız Teknik Üniversitesi, Fen Bilimleri Enstitüsü, Yüksek Lisans Tezi, 94s, İstanbul.

[9] Isobe, T., Feigelson, E.D., Akritas, M.G., Babu, G.J. 1990. Linear Regression in Astronomy I. The Astrophysical Journal, 364, 104-113.

[10] Judge, G.G, Grıffıths, W.E., Hıll, R.C., Lütkepohl, H., Lee., T. 1985. . 2nd edition. The Theory and Practice Of Econometrics. John Willey\&Sons. Canada, 999s.

[11] Genç, A., Karadavut, U., Palta, Ç. 2010. Lineer Olmayan Bayesci Regresyon ve Tarım Alanında Bir Uygulama. TÜBAV Bilim Dergisi, 3(3), 250258.

[12] Tiao B., Zellner, A. 1964. Bayes's theorem and the use of prior knowledge in regression analysis. Biometrika, 51(1/2), 219-230.

[13] Gasım, N. 2013. Bayesyen Model İle Doğrusal Regresyon Modellerinin Karşılaştırılması Üzerine Bir Uygulama., Dokuz Eylül Üniversitesi, Sosyal Bilimler Enstitüsü, Yüksek Lisans Tezi, 91s, İzmir.

[14] Saraçlı, S., Çelik, E. 2012. Metot Karşılaştırma Çalışmalarında Bland-Altman ve Tip II Regresyon Analizinin Karşılaştırılması. Düzce Üniversitesi Sağlık Bilimleri Enstitüsü Dergisi, 2(1), 11-14. 